\title{
Natural Resource-Based Socio-Economic System of Local Communities: Vulnerability and Adaptation to Climate Change
}

\author{
Sergii Kyryziuk $^{1 *}$, Viktor Yarovyi ${ }^{1}$, Igor Prokopa ${ }^{1}$, Mariia Lukyanova ${ }^{1}$ \\ ${ }^{1}$ Department of Economy and Policy of Agrarian Transformations, Institute for Economics and Forecasting of the National Academy \\ of Sciences of Ukraine, Kyiv, 01011, Ukraine
}

\begin{abstract}
Local rural communities challenge due to regional disparities on conditions and features of economic, infrastructural, social development etc. Most rural communities are strengthened by natural and environmental bases for economic development compared to urban areas. But during the last two decades they face the global challenge - climate change, which takes a risk of socio-economic system (SES), based on natural resources use. Agriculture and natural-based activities are the most vulnerable systems to climate change. This study aims to test the possibilities for Ukrainian local rural communities to adapt their SES, which are based mainly on natural resources use, toward the building of more resilient to climate change systems. Here, we develop the framework for assessment of vulnerability of community' SES to climate change, using the integrated indicator-based approach. We estimate the Vulnerability Index for six rural communities, describing the integrated level and by subsystems level of vulnerability. Our assessment confirms the high vulnerability of agriculture and natural ecosystem to climate change. It is a crucial challenge for further socio-economic development of the rural SES with the monofunctional economy which is based on natural resources use. In addition, the problem is exacerbated by the high vulnerability of the social system and infrastructure for most studied communities. Understanding the vulnerable subsystems of community' SES ensure timely response and the development of concrete policy actions at the community and state levels. In this study we substantiate the hotlist of actions for the most vulnerable subsystems.
\end{abstract}

\section{Introduction}

We argue that the ecological component affects the formation of the living space of rural residents. There are at least two most important aspects of such an impact in rural areas as follows:

First, the general climate changes affect the characteristics of the rural living space due to extreme weather events, changes in temperature and patterns of precipitation and so on.

Second, it is an effect of the large corporate farming. There is a dual structure of Ukrainian agriculture represented by large corporate farms and small individual farms. Among the most distinguishing features of the corporate land use are the following: excessive land concentration, intensive use of local natural resources and infrastructure, focus on the most profitable crops without proper crop-rotations causing soil depletion and others. Usually, corporate farming is more unsustainable comparing with small individual farms in terms of balancing the major components of sustainable development as economic, social and ecological.

For a long time, the term 'sustainable development' meant, first of all, that natural systems are able to provide both natural resources for the economy and quality ecosystem services for the whole society. According to the modern understanding of the concept, using the term 'sustainable development' in this study, we emphasize not only the importance of the environmental sustainability, but also the necessity to balance environmental protection with the economic and social development.

There are lots of evidences that Ukrainian corporate farms, trying to maximize their own profit, ignore social and environmental issues negatively affecting local rural communities. For instance, intensive corporate land use and animal breeding leads to depletion and pollution of local water resources, including drinking water sources for local residents, excessive use of chemicals on the corporate fields causes increased incident of respiratory diseases, leads to disappearance of pollinating insects, decreasing harvest in individual gardens of local households. At the same time, corporate farms actively use the local communal infrastructure without any significant input to maintain or restore it (for instance, heavy tracks with grain broke local roads).

All together, the mentioned ecological factors strongly determine the characteristics of local living space in rural areas. Such an influence is especially significant at the territories and in communities with local economies based primarily on the use of natural resources because of increased competition for resources that has a pressure on living space.

Ukrainian administrative subdivision significantly determines the patterns of local economies. Ukrainian territorial reform resulted in establishing new 
administrative units of basic level - territorial communities, which are the principal units of the administrative divisions of Ukraine. As of beginning of 2021, 1438 new UTCs - so called "United Territorial Communities" (without the capital city Kyiv and communities in the occupied territories) are fully functional that means they have their own local financial budgets and relations with the state budget.

The territorial communities are very different in their characteristics, namely area, urban and rural population, economic structure, financial autonomy and others. Most of the rural territorial communities are subsidized from the state budget, and the share of state subsidies and grants constitutes $40-70 \%$ of all their budget revenues. Except state subsidies and grants, taxes are the most important source of local budget revenues, but it is limited because the tax base remains relatively narrow in many rural economies. It is a constraint for local development of such territorial communities.

Agriculture is the main economic activity in most of rural territorial communities, creating the basis for local autonomy and providing financial capacity to realize local social and economic development programs.

Rural communities strongly depend on agriculture that provide financial flows allowing to fund local social and economic development. Almost 3 million people are engaged in agriculture [1]. Ukrainian agriculture has a dual structure with two basic types of agricultural producers, namely the corporate (agricultural corporations) and individual or peasant (private and subsidiary farms) ones. The corporate farms focus on commercial and export-oriented crops, while individual farms target the domestic market.

Except agriculture, such sectors as trade and social infrastructure are also important for employment of rural population $(1 / 4-1 / 3$ of formal employment in rural areas), but provide less for local budgets.

The increase in agricultural production capacity in Ukraine, which has taken place over the last decade, is largely due to the stock of unrealized agricultural potential [2]. In addition, the impact of global climate change also provided a positive effect to the increase of agricultural production by reducing the negative effects of certain weather and climatic factors (reducing freezing, increasing heat supply). However, the partly positive influence of climatic factors has a fairly pronounced regional character. In the south-eastern and southern regions, global climate change has become threatening in the last 2-3 years due to a sharp decline in moisture supply, increased moisture evaporation, which has increased the risks and scale of crop loss [3].

Climate risks pose a threat not only to individual farmers, but also to communities whose incomes depend on their efficiency. While the state is working on developing and implementing mechanisms to reduce production risks (resumption of partial financing for risk insurance, debt relief for climate-affected farms, etc.), local communities are left alone with the problem of budget revenues, unemployment and others.

The research objective of this study is to test the possibilities for Ukrainian administrative units of basic level to adapt their local development strategy, which are based mainly on natural resources use, toward adaptation to the climate changes and deal with other environmental challenges in order to mitigate their negative impact on the living space, especially in rural areas.

\section{Materials and Methods}

\subsection{Data and analysis of natural resources availability}

For the analysis, we used open local data and data provided by self-governments of six selected UTCs as follows: Buzhanska (hereinafter referred as Bzh), Vytvytska (Vt), Vovkovynetska (Vk), Losynivska (Ls), Novoslobidska (Ns) and Schumska (Sch). Selected UTCs represented different Ukrainian regions (Fig. 1) and three of the four natural and climatic zones, covered above $90 \%$ of the Ukraine' territory (the forest-steppe (Ns, Vk, Sch, Ls), steppe (Bzh) and the Ukrainian Carpathians (Vt). The last is quite important in terms of the objective of this study - assessing the impact of climate change, which have different effects depending on the zone [4].

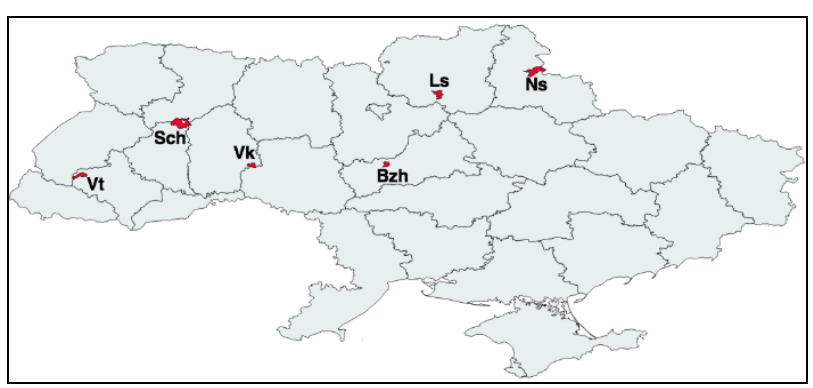

Fig. 1. Spatial allocation of the studied UTCs

For the analysis of local resources, we used data on on soils, natural reserves, mineral deposits from the State Land Cadaster, data on forests from State Forest Cadaster, data on licenses to use mineral deposits from State Service of Geology and Subsoil of Ukraine, data on state supervision on land use obtained from the State Service of Ukraine for Geodesy, Cartography and Cadastre, data on land covers obtained from satellite images for 2016-2018 and data on areas under agricultural crops in 2019 obtained from the State Land Cadaster [5].

Economic characteristics of agricultural lands are obtained from the official maps of natural and agricultural regions of Ukraine (prepared as a part of monetary assessment of agricultural land).

We used data on legal persons and individual entrepreneurs from the State Register to analyze economic activities and economic potential of UTCs [6]. We used also data on local budgets obtained from the official State online portal on local budgets [7].

We conducted two surveys in selected communities to get data on vulnerability of UTCs to climate changes: one investigates the opinion of local governments, involved in the development of local socio-economic strategy, programs and measures, on climate change issue; second investigates the opinion of local rural inhabitants, faced with the effects of climate change. We developed a questionnaire based on [8], which was distributed among 
the focus groups of respondents. Also, we gathered the assessment of climate change impact on SES in the different natural and climatic zones from the climate-related practitioners and scientists.

\subsection{Climate change impact}

For the assessment of UTCs vulnerability to climate change we used the framework consisted of the three components: factors of climate change impact; elements or subsystems of UTC' SES; vulnerability index (Fig. 2).

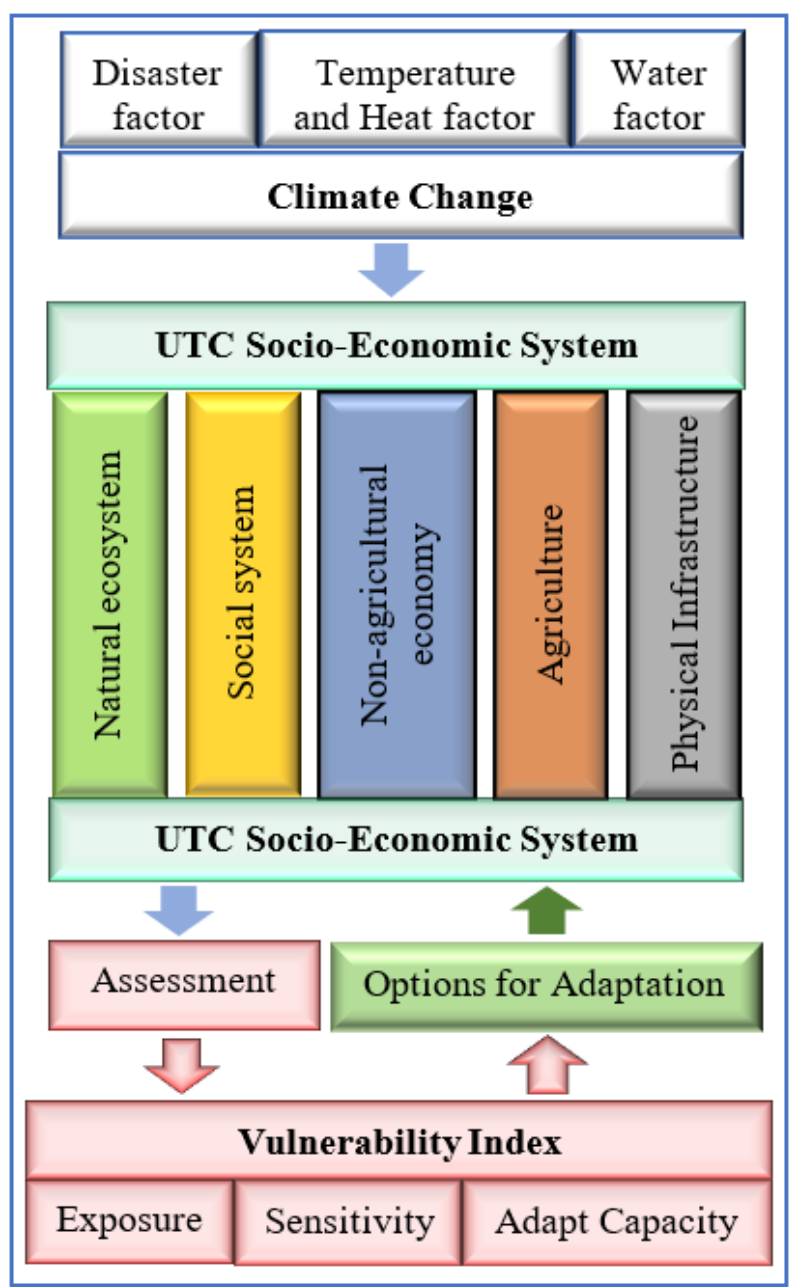

Fig. 2. Framework for assessment of community vulnerability to climate change

Methodologically this framework takes the IPCC concept on vulnerability [9] as a function of exposure, sensitivity and adaptive capacity and uses the indicatorbased approach as a most common for the assessment [10, 11]. Disaster impact (in particular, hydrometeorological events), air temperature and heat stress, precipitation and water availability changes are the key three factors, described the exposure socioeconomic system of UTCs to climate change. Also, each SES is tested for their sensitivity and adaptation capacity to climate change though the numerous of quantitative and qualitative indicators. The qualitative indicators were collected from the three groups of expert survey: UTC representatives, local inhabitants and scientists, and the quantitative indicators - from official national and local statistical sources, in particular, listed in the 2.1 chapter. Besides, we used the results of the Ukrainian hydrometeorological Institute [12] on climate change projections, in particular, precipitation, average and extreme air temperatures etc.

The qualitative indicators have the three-mark scale: low, medium and high level of vulnerability. The quantitative indicators were normalized also to the threemark scale. Sum of marks for each of subsystems comparing with the maximum level represents the subsystem vulnerability based on the following scale: below 30 percent of maximum level - low vulnerability, from 30 to 60 percent of maximum level - moderate vulnerability, and more than 60 percent - high vulnerability. The SES vulnerability index applies an equal weight sub-systems vulnerability index.

\section{Results and discussion}

\subsection{Availability and potentials of natural resources for local development}

All six selected ATC have natural resources sufficient for sustainable development. At the same time, they are very different by the composition of natural resources, possibility and potential for their use. The ATC are situated in different natural climatic zones, have different areas and landscapes etc.

The main natural resources are the following: land, water, forests, minerals, soils and climate.

Being a constant and regular source of revenue for municipal budget, land or territory is a resource that is one of the most important for sustainable development of local communities (table 1). Economic potential of the land area depends very much on its functional structure. For instance, substantial areas of Vt UTC are covered by mountain forests and Ns UTC has a significant share of natural protected areas, which means low economic pressure on that lands. As opposed to such a low economic pressure on lands of Vt and Ns UTCs, land area of Sch OTG is densely populated and provides a high rate of economic output.

Table 1. Land resources of local communities (UTCs)

\begin{tabular}{|l|c|c|} 
UTC & $\begin{array}{c}\text { Territory, square } \\
\mathbf{k m}\end{array}$ & $\begin{array}{c}\text { Territory per 100 } \\
\text { inhabitants, } \\
\text { square } \mathbf{~ k m}\end{array}$ \\
\hline$B z h$ & 136,20 & 3,99 \\
\hline$V t$ & 154,94 & 2,62 \\
\hline$V k$ & 109,92 & 2,48 \\
\hline$L s$ & 189,82 & 3,10 \\
\hline$N s$ & 356,98 & 10,69 \\
\hline$S c h$ & 499,50 & 2,37 \\
\hline
\end{tabular}

Agriculture is the main economic activity and way how the land is used in all UTCs except Vt UTC with its forestry, but even for population of Vt UTC the output from their agricultural land plots plays the most important role for their well-being. The combination of territorial characteristics and natural resources used in 
agriculture (particularly soils) is the basis of the local agricultural natural potential.

Comparing with other communities, Bzh UTC has the best soils providing the highest land rent. There are estimated land rent values officially calculated for different natural agricultural districts in Ukraine. This value for arable land of Bzh UTC is 43801 UAH per ha for $1 / 3$ of its territory and 28378 UAH per ha for other $2 / 3$ of the territory. For other UTCs the values are as follows: 32221 UAH for Ns UTC, 28213 UAH for Ls UTC, 22990 UAH for Sch UTC, 16218 UAH for Vk UTC, and 6893 UAH for Vt UTC.

The common feature for Bzh, Vk, Ls, Ns and the lowland part of Vt UTC is the excessive shares of agricultural land in their territory and arable land in their agricultural land. Such an economic pressure on land leads to violations of environmental standards, soil erosion, degradation of landscapes and other negative consequences.

Forest resources are very important of Vt UTC because $70.9 \%$ of its area are covered by managed forests. The share of area covered by forest is also higher than the average Ukrainian value (16\%) in Sch UTC (34.3\%), Ns UTC $(22.6 \%)$ and Bzh UTC (22\%). Forest covers $14.6 \%$ of all area of Vk UTC, and area under forest is very insignificant in Ls UTC.

Forest landscapes are valuable natural and recreational areas. Unfortunately, the UTCs use such their potential in inefficient and unsustainable way. It is true especially for Vt UTC, where there are processes of intensive cutting of woods leading to the deterioration of forest structure, soil degradation, floods and landslides.

The UTCs are also very different by their water resources.

The area of Bzh UTC belongs to the areas with poor water resources and water supply. The surface water outflow to small rivers and water levels in wells reduced in recent years. Vt UTC is situated in the Dnister River Basin, and the tributaries of the Dnister river contribute to the local tourism potential. Water resources are sufficient, but there is no communal water supply there. The community uses underground water for business and social needs. There is no communal central sewage system, so surface and groundwater pollution became a serious problem. Water resources of Vk UTC include small tributaries of the river Southern Bug and ponds. The increasing degradation of surface and groundwater water quality, loss of water quantity are the important problems for the community. Ls UTC has the similar problems. Its water resources are represented by small river system and underground waters. Large industrial corporate farms use the water resources in intensive way that leads to overexploitation of water and depletion of water resources. The situation with water resources in the Ns UTC is better than in other UTCs. Its water resources are represented by the Seym River and its tributaries. There are also ponds in all settlements. The economic pressure on water resources is also relatively low. In this community, their water resources are very important components of the local natural potential that is protected in reserves. The water resources of Sch UTC are represented by small tributaries of the Pripyat River
Basin, ponds. Much of the area belongs to the protected riverbank territories. The main problems here are pollution of surface waters by local business, and pollution of local drinking water sources.

While come UTCs are situated on the areas with poor water resources, other UTCs have sufficient water resources but suffer from pollution of surface and underground waters. Water quality declined in all UTC during last decades. Recent climate changes also affected water quantity. All mentioned above are the factors to be taken into account for the local development strategies.

Minerals. All UTCs have local mineral deposits (peat, chalk, sand, clay, sapropel and others) on their territories, but not all deposits are being exploited because of different reasons (small reserves, danger to the environment etc.). Some UTCs have also mineral deposits that are of national interest (oil and natural gas).

The common feature in exploitation of local subsoils and mineral resources is the fact that usually all rights belongs to third parties, which registered outside communities. It means that UTCs have little control over and benefit minimally from the extractive projects. Another common feature - some mineral deposits, which were recognized impractical to exploit during Soviet era, could became an important factor of local economic development in the current context when local authorities have more power.

Natural reserves, recreational resources. According to the Ukrainian legislation, the share of natural reserves and other territories with the similar conservation status should be at least $10.4 \%$ of the total area. In some analyzed UTC such a share is even higher now. There are natural reserves and other territories with similar status of special natural value (like objects of Emerald Network) in Vt, Ls, and Ns UTCs. Such areas have significant recreational and educational potential, which is not yet used. There is also a common risk of negative economic impact on such natural areas in the UTCs.

At the same time, there are no even territories that potentially could pretend to be transferred to the status of protected in Bzh UTC and Vk UTC.

Another common problem for all communities in their resource use is the fact that not all natural resources have been inventoried and registered in state cadasters. It creates problems both for the planning of efficient local resource use and for the effective protection of unregistered resources, especially for the communal lands. For example, about a quarter of communal land still remained unregistered in the land cadaster in 2020. Inventory of local natural resources is one of the highest priorities for all UTCs.

\subsection{Climate change: opportunities and challenges for local development}

The investigated UTCs are located in the different agroclimatic zones of Ukraine: the forest-steppe (Bzh, Ns, $\mathrm{Vk}$, Sch), the forest (Ls) zones and the Ukrainian Carpathians (Vt). During the last two decades the traditional climatic conditions were changed under the global warming: $0,8-1^{\circ} \mathrm{C}$ compare to the average for the 
1961-1990 period, including $1-2^{\circ} \mathrm{C}$ - for winter season. And the traditional borders of the agro-climatic zones shift north by $200-300 \mathrm{~km}$ [4]. As a consequence, two UTCs belong to the new agroclimatic zones: Ls UTC forest-steppe instead forest and Bzh UTC - steppe instead forest-steppe.

For further decade (till 2030) it is forecasting the significant increase of the yearly air temperature and slight growth of precipitation in Ukraine in general: up to $0,5^{\circ} \mathrm{C}$ and +5 percent comparing with 1991-2010 respectively. But considering the higher level of evaporation and the lower frequency of rainfall, there is a risk of the lower moisture supply and availability of water resources. The higher increase in precipitation occurs in spring and winter seasons. Instead, in the summer months, the amount of available precipitation reduces, as well as in the first autumn months, which challenges for winter sowing campaigns. But note that the forecasts, averaged within the different climate models, may have both arid (as the 2019/2020 season) and humid (as the 2018/2019 season) scenarios of global climate change.

In general, all of the investigated UTCs challenge by hydro-meteorological factor, in particular, hail, thunderstorms, squalls, strong gusts of wind. However, most UTCs face with problem of precipitation scarcity, except Vt UTC, which challenge by flooding.

Another climate factor, effected on UTCs vulnerability, is high air temperature and heat stress. In Ukraine, droughts, which cover up to $30 \%$ of the country, already occur once every 2-3 years, and in the future their frequency will double. After long-term drought there is high risk of extreme hydro-metrological disasters, causing great damage to the entire socioeconomic UTCs' system.

The above-mentioned climatic factors impact on, first of all, agriculture, which leads to lower crop yields, especially, in the central, southern and eastern regions of Ukraine (in particular, in Bzh UTC). Besides, climate factors impact on energy production and supply due to higher demand for water distribution, air condition etc. On the other side, energy infrastructure stresses by extreme meteorological damages (storms, wind, freezing etc.). These are only the most visible and frequent negative impacts and vulnerable sectors to climate change.

In general, our assessment confirms the exceeding the threshold of the high vulnerability of the investigated UTCs SESs, except Ls UTC (but it is to close to threshold -0.59 ). But there is significant variability of UTCs vulnerability between the subsystems (Fig. 3).

Agriculture is the among the most vulnerable UTCs socio-economic subsystem. The assessment reveals that agriculture of all UTCs (Bzh, Vk, Ns and Ls) are high vulnerable (agriculture vulnerability ranges from 0.64 to 0.80 ) to climate change due to (1) high exposure to drought and land erosion, (2) high sensitivity of agriculture to climate change due to high percentage of arable land and rain-fed crop area, high level of monocropping in agricultural practice), (3) low adaptive capacity of farming system due to the poor implementation of the modern agricultural practice (lowand no-till) and the innovative irrigation system, unbalanced fertilization of crop land, despite the high level of financial assets, gained from agricultural activities during the last decade.

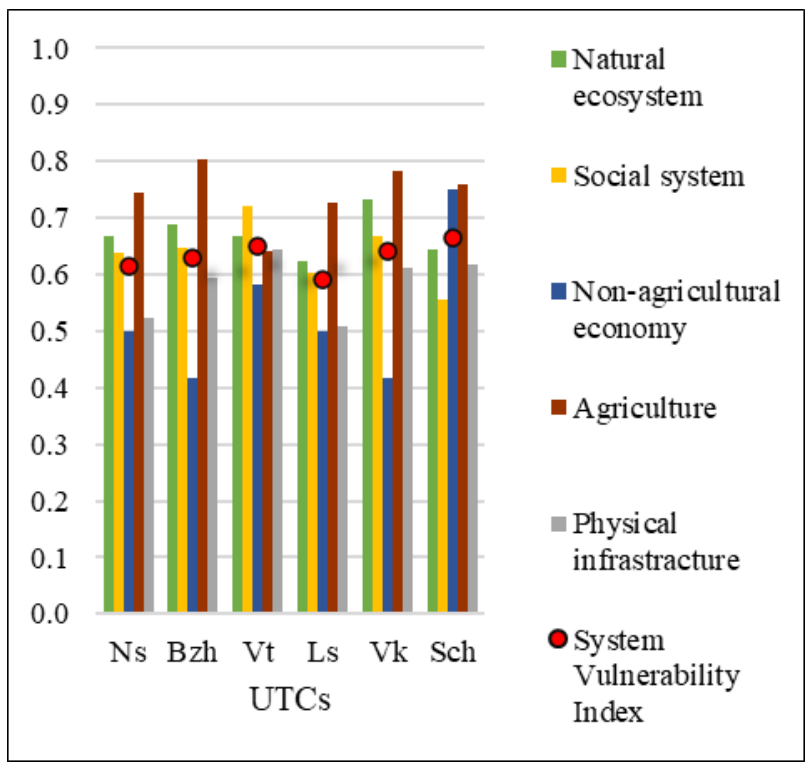

Fig. 3. Communities vulnerability to climate change

Natural ecosystem is the next most vulnerable subsystem with also high vulnerability index for all UTC (0.62-0.73). High vulnerability of natural ecosystem causes by high sensitivity of ecosystem to warmer climate, which are detected by the key indicators, like tree pests and diseases, lower river runoff, lower biodiversity etc.

Natural ecosystem can eliminate some of these negative effects thought self-reproduction or selfrenewal. But this ability is limited by the intensive exploitation of natural resources and high anthropogenic pressure (for example, soils do not cope with the function of filtering groundwater, supersaturated with mineral fertilizers, etc.).

Hereby, high vulnerability of agriculture and natural ecosystem is crucial challenge for socio-economic development of the investigated UTCs with monofunctional economy which are based on natural resources use.

Moreover, UTCs SESs challenge by low incomes and high poverty rate of rural families (in particular, due to the high dependency of family income from farming household), unfavorable age structure of rural society, low level of awareness and activities of the rural inhabitants. Our study reveals the high vulnerability of the social subsystem for almost all investigated UTCs (except Sch UTC), which ranges from 0.60 to 0.72 .

In the process of decentralization of power, most rural UTCs inherited the destroyed physical infrastructure. Although the government provides the support to the development of infrastructure through the different subventions and subsidies, it is not enough to overcome this problem. Therefore, communities should try to find internal assets to renovate rural physical infrastructure on their own. So, it is not surprising that our assessment of infrastructure vulnerability to climate change confirms this issue. And although there is slight 
exceeding of the threshold of the high vulnerability for the investigated UTCs, it does not provide any optimism concerning the UTCs resilience to climate change.

And finally, the relatively lower level of vulnerability of the non-agricultural economy $(0.42-0.58)$ of the investigated UTCs is mainly due not to its lower sensitivity and higher adaptation capacity, but to its underdevelopment (except Sch and Ls UTCs with few food processing enterprises). On the one hand, it strengths the capacity (in particular, due to the low negative environmental impact), and on the other hand it challenges due to the limiting financial resources for the implementation of adaptation policy measures.

\section{Conclusions}

Decentralization reform in Ukraine and transition of the power to the local level has exposed a number of problems in the field of local socio-economic development, especially rural development. Abandoned infrastructure, a monofunctional economy, and a weak level of human capital are just the main challenges to socio-economic development. At the same time, local communities have faced a global challenge - climate change. While local communities are already aware of the socio-economic challenges and are trying to take them into account in their development strategies, global climate change is fragmentary understood by local selfgovernments and communities. They don't take it into account in their long-term development strategies and plans.

UTCs, which are selected for this study, belong mainly to rural communities with a monofunctional economy based on the intensive use of natural resources, mainly agricultural land, which is very important resource for local communities. At the same time, under the climate change, the value of water resources increases exponentially, and it affects almost all elements of the local SESs.

The methodological tool we developed for assessing the vulnerability of the SES and its components to the climate change is adapted to use available national and local data sources. Thus, it could be used to analyze all Ukrainian UTCs, despite some limitations of the developed method. In particular, we understand some risk of subjective assessment of climate change effects on UTC' SES within the collected surveys. We gathered the professional assessment (scientists and practitioners in the field of climate change impact) to minimize this risk.

The obtained results confirmed the assumptions about the high vulnerability of local SESs to climate change. The most important elements of the local SESs are agriculture and and natural ecosystem, and they are the most vulnerable to climate change.

Possible scenarios of climate change indicate a further increase in temperature, which with slight increase in annual rainfall will result in further reduction of groundwater levels. This will negatively affect the availability of water resources from traditional sources (surface sources) and will increase the demand for the use of deep-water sources. It is a significant challenge for the monofunctional economies of the UTCs analyzed in this study.

Effective measures to reduce the negative effects of drought and reducing moisture supply are the following: implementing the moisture-saving tillage technologies; using rainwater for agriculture and other purposes; replacing traditional crops with drought-resistant ones (for example, replacing potatoes with chufa; traditional cereals (wheat, corn, barley) with millet, sorghum, chickpeas, etc.).

Additional effective measures to reduce the vulnerability of agriculture are the insuring production risks and increasing areas under perennial crops and pastures to reduce the share of arable land with a positive effect on the sensitivity of agricultural land use to climate change. Currently, the Ukrainian government is studying the possibility of introducing preferential risk insurance in agriculture, which is especially relevant after the large-scale drought in 2020.

The key measures to overcome the vulnerability of the local infrastructure are the following: enhancing the readiness and opportunities of local communities to eliminate the consequences of adverse hydrometeorological phenomena (formation of mobile local teams of volunteers, purchase of special equipment and tools) and development of flooding prevention networks (support the working conditions of drainage, sewerage and water networks).

We argue and the practice confirms that, at the local level, small individual farms usually have higher potential for adaptation to climate change. In general, the potential for adaptation depends not so much on land size, but mainly on land use strategy. In this context, large corporate farms that renting their land from small landowners and small family farms have different motives for their strategies. Large corporate agro holdings have poorer connections with the local communities where they operated under the lease agreements with local land owners. They are not diversified and oriented mainly on production of wheat, maize, rapeseed and sunflower that are most commercially attracted agricultural crops. Such corporate farms are often registered and pay their taxes outside the local communities where they cultivate land rented from local peasants. Usually, large corporate farms don't really care about interests of local communities because their economic interest is the only driving force of their activities.

At the same time, owners of small family farms live close to their land plots. Such farmers and members of their families are integrated in the communities and shares the interests with other local rural residents. They are more dependent on the opinion of their neighbors. Small local farms are more likely to act in a responsible way that meet the local sustainable development goals. At the same time, they are more mobile to change their plans, diversify the crops, and face new environmental challenges.

The mentioned above means the excessive concentration of agricultural land use, which is forced by corporate farms, leads to declining local agricultural 
potential for adaptation to climate change. That is why it is the interest of local authorities and communities to state the priority and implement the support measures for family farming into their local development strategies.

\section{References}

1. Statistical Yearbook of Ukraine 2019. State Statistics Service of Ukraine. (2020) [On-line]. Available at: http://www.ukrstat.gov.ua/druk/publicat/kat_u/2020/ zb/11/zb_yearbook_2019.pdf

2. Alexandratos, N.; Bruinsma, J. World Agriculture Towards 2030/2050: the 2012 revision. FAO, ESA Working paper No 12-03, (2012).

3. Ackermann A. Climate change may prevent Ukraine from becoming agricultural superpower [On-line]. Available at: https://www.atlanticcouncil.org/blogs/ukrainealert/cl imate-change-may-prevent-ukraine-from-becomingan-agricultural-superpower/

4. Technology Need Assessment Report. Adaptation. Ministry of Ecology and Natural Resources of Ukraine (2019) [On-line]. Available at: https://techaction.unepdtu.org/wpcontent/uploads/sites/2/2019/09/final-ukraine-tnaadaptation-report.pdf

5. Public Cadastre Map. State Land Cadaster of Ukraine. [On-line]. Available at: https://map.land.gov.ua/?cc=3461340.1719504707,6
$177585.367221659 \& \mathrm{z}=6.5 \& \mathrm{l}=\mathrm{kadastr} \& \mathrm{bl}=$ ortho $10 \mathrm{k}$ all

6. USR Register. [On-line]. Available at: https://irc.gov.ua/en/el_reg

7. Open budget. [On-line]. Available at: https://openbudget.gov.ua/local-budget

8. National Climate Vulnerability Assessment: Ukraine. Climate Forum East (CFE) and NGO Working Group on Climate Change (2014) [Online]. Available at: https://climateforumeast.org/uploads/other/0/708.pdf

9. IPCC. Climate Change 2007: Impacts, Adaptation and Vulnerability; Contribution of Working Group II to the Fourth Assessment Report of the Intergovernmental Panel on Climate Change (IPCC); Cambridge University Press: Cambridge, UK (2007).

10. Neset, T.S.; Wiréhn, L.; Opach, T.; Glaas, E.; Linnér, B.O. Evaluation of indicators for agricultural vulnerability to climate change: The case of SwediSch agriculture. Ecol. Indic. 105, 571580 (2019).

11. Wiréhn, L.; Danielsson, Å.; Neset, T.S.S. Assessment of composite index methods for agricultural vulnerability to climate change. J. Environ. Manag. 156, 70-80 (2015).

12. Results of scientific research projects. Ukrainian Hydrometeorological Institute. [On-line]. Available at: https://uhmi.org.ua/project/rvndr/ 